\title{
Study on Design and Construction Method of New Composite Brick
}

\author{
Shan Chen ${ }^{1, a}$, Chuanlong Zou ${ }^{1, b^{*}}$ \\ ${ }^{1}$ College of Civil Engineering and Architecture, Nanning University, Nanning, Guangxi 530200 \\ a346201114@qq.com, b236685299@qq.com
}

Key words: composite brick, construction technology, rural housing,design

Abstract. In order to study the brick masonry structure in rural areas, a new type of composite brick is designed with concrete and steel plate as raw materials. On this basis, the rapid construction technology is analyzed, which provides a new design of low-rise building brick masonry in rural areas. The new design scheme has certain significance for the use of masonry structure and masonry technology in rural areas.

\section{Preface}

Rural construction of China is mainly self-built, and more by fired common bricks that affected by natural disasters, such as, in recent years, earthquake, typhoon and other natural disasters. Because of fired common bricks with bending, poor tensile properties, poor overall stiffness and other shortcomings, building bearing capacity is weak ${ }^{[1-6]}$. Therefore, improving the shear and seismic performance of masonry structure to meet the development need of rural construction is really important. Chinese scholars carry out a lot of work on the design and development in this respect. Yan Liu etc ${ }^{[7]}$ propose the design of masonry wall with lightweight concrete-filled steel tube core column and thermal-insulation sandwich, which has good seismic performance and thermal performance, and is the seismic wall of insulation load-bearing integrated and low cost. YuLi Chen etc $^{[8]}$ outsource steel plate in brick columns' surface to form the combination of steel plate-brick masonry,which improve the original masonry bearing capacity, ductility and the yield of coated steel plate. Yuxiang Pan etc ${ }^{[9]}$ study in depth on the steel-brick masonry composite structure transformation technology, test the axial compression performance of special-shaped column with the steel-brick masonry composite and provide reference for its load conditions. Huayun Sun etc ${ }^{[10]}$ design the composite brick in high temperature furnaces and thermal equipment of key orifices, outer surface is formed by simple geometries to form complex spatial geometry, so that these composite tiles are interlocked and uniformly stressed and structurally firm. However, most of the scholars who study the masonry brick are based on the use of the city, and mostly outsourcing steel are based on concrete to form brick masonry, the rural areas of brick masonry research is still relatively small, so the paper design a new type of brick masonry made of concrete and steel plate. The rapid construction method of the new composite brick is analyzed. On this basis, it is applied to the construction of rural areas.It has a certain meaning on promoting the application and development of brick masonry structure in rural areas.

\section{Design of new composite brick structure}

As the brick and concrete structure in rural areas are mainly fired common bricks, the main construction methods is masonry,and fired common bricks is relatively low strength, and masonry construction process is slow, in order to improve the brick masonry strength, and speed up the construction of brick masonry structure in rural areas, a new type of composite brick is designed, in 
this paper.The composite brick is mainly composed of concrete, rectangular closed steel plate and steel pipe with gap, The concrete form is shown in Fig.1. Fig.1 (a), (b), (c), (d), respectively, are the composite brick schematic diagram, rectangular closed steel plate schematic diagram and the appearance of composite brick diagram, the composite brick positioning tank diagram. From the figure, the composite brick body is fitted with a rectangular closed steel plate frame.In order to increase the adhesion between the steel plate and the concrete for good bonding performance under the external load, and the cylindrical steel pipe with the notch is welded around the rectangular closed steel plate, the axis of steel pipe and the outer surface of steel plate are perpendicular to each other, and the circumferential surface is a non-closed surface. The steel pipe of each face can be set in different positions as needed, as well as different quantity and cross-sectional area. The cutouts of the steel pipe are different from each other and are random, allowing the concrete to be poured more effectively, with a gap area less than or equal to $25 \%$ of the total area of the circumference. The upper end surface of the combined brick body is provided with a positioning groove, and the lower end surface is provided with a positioning protrusion matching the positioning groove, and the distance $\mathrm{n}$ between the positioning groove and the center axis of the positioning projection to the end face of the brick body side is smaller than the distance $M$ as shown in Figure 1 (c). The support frame inside the brick body is mainly composed of a steel plate frame and a steel pipe which welds its surface. The gap on the steel pipe is easy to pour concrete, so that the steel frame skeleton and the concrete material work together to form a single steel frame-concrete composite brick as shown in Figure 1 (d). Before the mold is made, the central axis of the steel plate frame must coincide with the central axis of the brick body, thus increasing the strength of the composite brick to a certain extent.

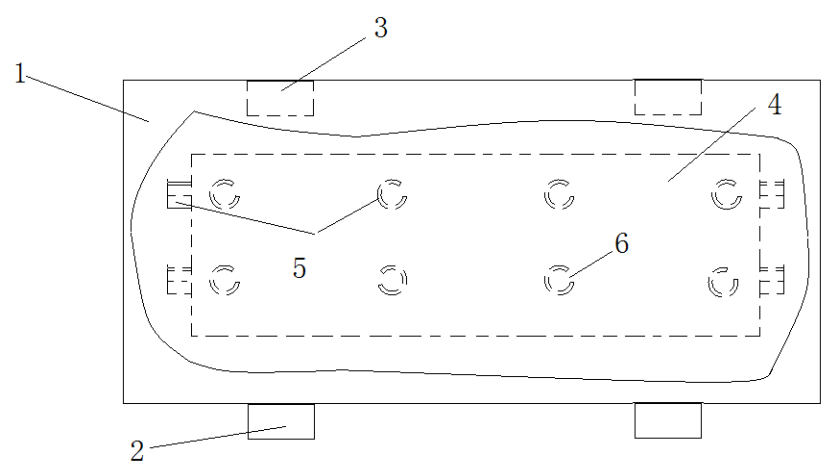

(a) The composite brick schematic diagram

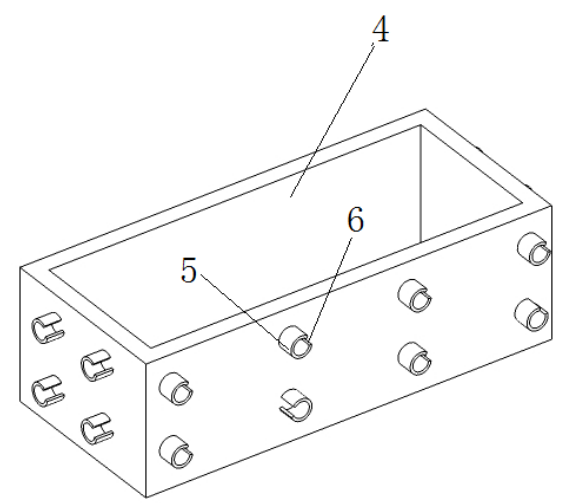

(b)The schematic diagram of steel plate frame structure

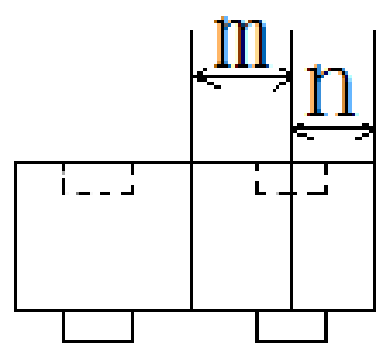

(c)The schematic diagram of the distance between the composite brick positioning groove (positioning protrusion) relative to the brick surface and middle plane 


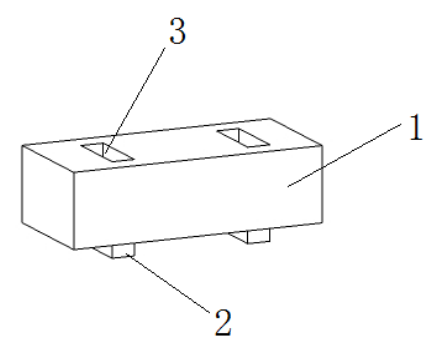

(d) The schematic diagram of composite brick's appearance

Fig.1 Composite brick structure schematic diagram

Note:1-brick body,2-positioning protrusion,3-positioning groove, 4-steel plate frame,5-steel pipe, 6-gap (same below)

\section{Rapid construction method of new type composite brick}

Firstly, The same layer of composite brick is plated along the length of the brick body, the adjacent brick layers are inserted into the positioning grooves on the upper end faces of the lower brick bodies according to the positioning protrusions of the upper end faces of the upper brick bodies to combination pile one by one as shown in Fig. 2 (a), and then, the gap between the same adjacent layer and the upper and lower brick body is filled with mortar as shown in Fig. 2 (b), it can speed up the construction of brick masonry methods to a certain extent, and the wall is easier to align.

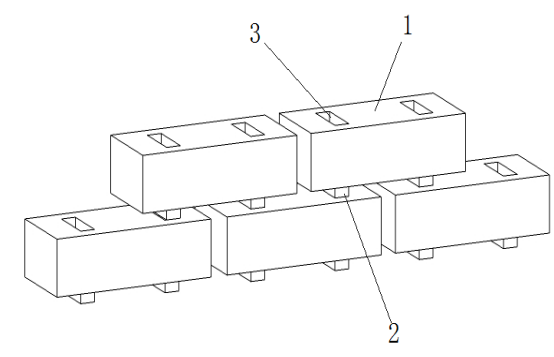

(a) The schematic diagram of composite brick stacking

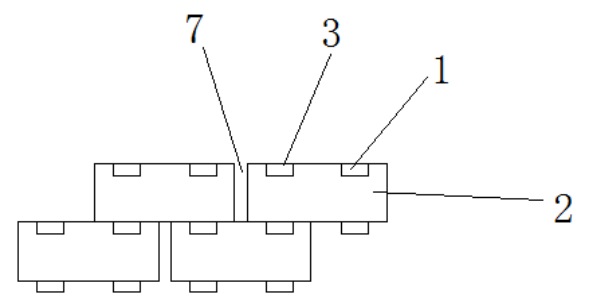

(b) The elevation diagram of composite brick wall

Fig. 2 Diagram composite brick wall(Note: 7-gap)

The design of composite brick size can be arbitrarily set with the size of the building masonry, and it can be mass production in the factory. The wall is formed, matching according to the positioning groove and positioning protrusion of composite brick, and the construction is speed, easy to leveling and alignment, bearing the load by the combined brick body itself. At the same time, the gap between the brick is fill with mortar, to ensure the ultimate wall integrity, improve shear performance and seismic performance of the masonry wall,and construction is convenience.

\section{Study on application of composite brick}

For the steel frame-concrete composite brick designed in this paper, the steel frame in the composite brick can improve the bearing capacity of the external brick body, and the adhesion between steel pipe that steel frame surround with gap, with the concrete material of brick body, can enhance the shear performance of composite brick, tensile properties.In addition,external positioning groove of the composite brick and positioning match correspondingly, and in the construction of the wall is easy to leveling, construction is speed.

The new steel frame-concrete composite brick is designed with steel plate, which has the advantages of strong resistance to compression, shear and bending, combined with concrete as composite brick can be applied to the construction of masonry houses in rural areas.It can increase 
the overall performance of masonry structure, and speed up the construction progress of brick masonry.

\section{Conclusions}

In this paper, the appearance and interior of steel frame-concrete composite brick are designed, and the construction method of the wall is introduced, its application in rural area is discussed. Compared with the performance of ordinary masonry tiles, due to the steel frame inside the brick body, it can improve its mechanical performance. The external design of the positioning groove and positioning protrusion is easy to construct, due to the corresponding matching in forming the wall. The design of this new type of composite brick has a certain reference significance for the research and application of masonry structure in rural houses.

\section{Acknowledgements}

Basic ability improvement project of young teachers in Guangxi Zhuang Autonomous Region (2017KY1441), scientific research project of Nanning University (2017XJ20, 2016XJ42).

\section{References}

[1] S H SHANG, X Z WEN. Building seismic strengthening practical technique about masonry and reinforced concrete structure in village buildings[J].Construction Tehnology,2010 (5) : 11-12.

[2] Y ZHANG, H S WANG, H CAI, et al. Investigation and analysis on seismic performance of stone masonry buildings in Fujian coastal area [J].Inland Earthquake,2016,(03):211-220.

[3] M B ZHANG. The research of future development direction of masonry structure [J].Shanxi Architectuer, 2015,(26):55-57.

[4] Q ZHOU, F SHAO,B T SUN. Investigation and analysis of seismic capacity of rural buildings in Jiangxi [J]. Earthquake Engineering and Engineering Dynamics, 2016,(06): 188-197.

[5] GE Xueli, ZHU Lixin, YU Wen. Overview of researches on disaster prevention of buildings in village and town [J]. Journal of Natural Disasters, 2014,(02):8-14.

[6] H T ZHAI, J F CAO,D D LI, et al. Seismic Intensity and Buildings Damage of 2011 Anqing Ms4.8 Earthquake [J]. Technology for Earthquake Disaster Prevention, 2011,(03): 276-283.

[7] Y LIU,Z Y ZHOU, W L CAO, et al. Study on seismic performance of the masonry wall with lightweight concrete filled steel tube core column and thermal-insulation sandwich[J].Earthquake Engineering and Engineering Dynamics, 2015,(01):223-230.

[8] Y L CHEN, S Y CAO,D H JING. Local buckling behavior of steel plate-masonry composite column subjected to axis force [J]. Building Structure, 2013,(S1):493-497.

[9] Y X PAN, S Y CAO,D H JING, et al. Experimental study on axial compression behavior of steel plate-masonry composite irregular columns[J]. Journal of Building Structures, 2014,(08):113-119.

[10]H Y SUN, Y B WANG, Y Y LIU, et al. Combination of brick production[A]. Hebei metallurgical institute,2006. 